\title{
Un reporter de guerre en temps de paix
}

\section{Didier LECLAIR, écrivain}

Quand son ami Jacques, rédacteur-en-chef d'un petit journal communautaire, lui demanda un texte sur les survivants victimes d'actes criminels, il pensa tout de suite à l'interview la plus difficile qu'il eut à faire dans son ancienne carrière de journaliste. Jacques voulait cet article pour sensibiliser les gens à la situation périlleuse des familles d'immigrants dont un membre devient criminel.

Durant sa longue carrière de reporter, il eut à couvrir des événements divers. Cela pouvait être des inaugurations officielles ou des manifestations de rue en passant par des litiges syndicaux ou encore des visites de dignitaires étrangers à Toronto. Tous ces reportages furent faits pour la radio de Radio-Canada. Il vint un jour toutefois où il n'était plus nécessaire et on le remercia pour ses services. Il n'était pas amer, juste déçu d'avoir été perçu par son employeur comme un fardeau.

Mais un an avant qu'on le remercie, il reçut un appel un soir alors qu'il s'apprêtait à se pencher sur un de ses romans qu'il écrivait la nuit.

- Guillaume?

- Oui. Qui est à 1'appareil ?

- Guillaume Evono, le reporter?

- C'est bien moi.

- Tu ne me connais pas. Mais je t'écoute à la radio.

C'est ainsi qu'il fit la connaissance de Sylvestre Bomboté, père d'un jeune Torontois d'origine africaine. Dans sa voix grave, il l'invita à passer dans le quartier de Regent Park où il vivait pour lui parler de son fils tombé dans la criminalité. Il ajouta qu'il était persuadé que cette histoire valait un reportage.

- Je ne sais pas. Il faudrait que je demande à...

- Viens demain. J'ai une vraie histoire pour toi.

- Mais...

- C'est comment? Tu as peur? Passe à dix-neuf heures, rien ne va t'arriver.

Bien sûr, il ne put écrire une ligne de plus après cet appel, intrigué par ce que cet inconnu avait à lui raconter. Il faut dire que l'idée d'obtenir un scoop aurait fait son affaire. Il savait que 
son poste de reporter pouvait être supprimé en tout temps. C'était une occasion en or de montrer à ses supérieurs qu'il était indispensable.

Le lendemain au soir, Guillaume était à l'heure. C'était une de ces journées d'hiver humides que Toronto enfilait les unes après les autres comme un chapelet sans miséricorde. Sa machine à enregistrer au bout du bras, le reporter cogna à l'adresse de l'inconnu avec une certaine appréhension. C'était un appartement modeste au rez-de-chaussée et le manque de lumière à l'extérieur accentuait la pénombre qui habitait ces lieux. L'homme était maigre, court et grisonnant. Son sourire ressemblait davantage à une grimace. Le journaliste n'eut pas à se présenter, l'hôte lui montra une chaise dans son salon grand comme un mouchoir de poche et aux murs nus et placides.

- Nous n'avons pas beaucoup de temps. Ma femme et mon jeune fils Firmin rentreront dans une heure. Je tiens à ce que tu sois parti avant. Mon épouse ne voulait pas que je t'appelle. Mais je lui devais ça.

- Tu devais quoi à qui ?

- Mon fils Marco. Il voulait être reporter, comme toi.

Il mit son micro sur la table, surpris par le dernier commentaire.

C'est sur ces mots que commença son entretien.

Ils firent les présentations officielles. Lui s'appelait Sylvain et venait du Cameroun. C'était un fan de Guillaume. Il l'avait convoqué pour parler de son garçon Marco, mort criblé de balles.

- Quatre balles dans le ventre, précisa-t-il. C'était il y a six mois et deux jours. Juste à une rue d'ici. Il m'a dit qu'il allait chercher quelque chose chez son copain. Il n'a pas précisé. Une heure plus tard, j'ouvrais la porte à la police. Quand ils m'ont dit qu'on l'avait abattu derrière un immeuble à côté d'une benne à ordure, j'ai failli vomir.

- Pourquoi est-il mort?

Il haussa les épaules.

- Ça avait commencé par la consommation de marijuana. On a constaté, sa mère et moi, ses yeux rouges, sa langue lourde et ses sautes d'humeur quand il était en manque. C'était la même chose tous les jours et sa chambre empestait cette odeur de chanvre que je ne supporte plus. On avait beau dire que c'était dangereux ce qu'il faisait, il nous riait au nez ! Et dans ce pays, on appelle ça de la «drogue douce ». Mes collègues, mon patron, même mon prêtre me trouvaient 
alarmiste. Pour eux, le chanvre, c'est inoffensif. Pas pour tous. Pas pour mon fils en tout cas. J'avais l'impression de voir ma maison brûler devant mes voisins indifférents.

- Ensuite ?

- On a arrêté de lui donner de l'argent de poche. Il s'est mis à vendre de l'herbe pour en consommer. Sa mère a trouvé une mini-balance pour peser sa marchandise dans la poche de son manteau. C'était le jour d'anniversaire de Joséphine et elle croyait que c'était un cadeau.

Sa voix perdit de sa contenance et Guillaume lui demanda s'il voulait arrêter un instant. Il accepta et se leva.

- Je perds mes bonnes manières. Nous n'avons plus de visiteurs depuis qu'il est mort. Tu veux boire quelque chose ?

Sylvestre revint avec un verre d'eau.

- Marco rentrait et sortait quand il voulait, surtout la nuit. Il allait en classe une fois sur deux. C'est lui qui m'a rendu si grisonnant. Nous avons essayé de l'encourager aux études car il écrivait bien! Rien à faire.

Ce père éploré passa sa main sur son visage comme s'il voulait se réveiller d'un cauchemar.

- Cette spirale vers sa fin, je la revois chaque jour. En l'espace d'un an, c'était un autre enfant. Il avait toujours de l'argent sur lui, puis il y a eu les tatouages, le pantalon sous les fesses et un pistolet dans son tiroir de chambre, sous des vêtements. C'est moi qui l'ai trouvé. Je cherchais de la marijuana à jeter. On a eu une grosse altercation. D'après lui, le pistolet n'était pas le sien. Il le gardait pour un copain. Mais je ne l'ai pas cru. Ce soir-là, je l'ai menacé de le dénoncer à la police. Il m'a pris par le collet et m'a montré son poing. J'étais devenu un traître.

- Et pourquoi n'avez-vous appelé la police à ce moment-là ?

- Une famille noire n'appelle pas la police facilement. On n'avait peur de l'altercation entre Marco et eux. On s'imaginait le pire. Ni ma femme, ni moi voulions en être responsable.

Sylvestre prit une grande respiration et observa Guillaume en silence. Le reporter continua sur sa lancée.

- Avez-vous cherché autre chose, un travailleur social, un groupe d'aide aux parents d'enfants toxicomanes pour aider Marco ?

- Bien sûr. Nous allions aux rencontres avec le travailleur social toutes les semaines. Mais sans Marco. Il ne voulait rien savoir. J'y ai croisé d'autres parents du quartier aussi perdus que moi. 
- La police a un suspect pour son meurtre?

- Non. C'est pour ça que je t'ai fait venir. Je veux qu'on parle de lui. Qu'il ne soit plus une statistique. Il s'appelait Marco Bomboté. Il avait dix-huit ans et voulait devenir journaliste. En tuant mon fils, son meurtrier a fait de moi une autre victime. Je ne sors plus dès que la nuit tombe, j'ai peur. Je me sens coupable de m'être disputé si souvent avec lui. Ma femme a perdu son emploi à cause d'une dépression et Firmin croit que la police fait exprès de traîner les pieds dans son enquête parce que son frère était Noir et trafiquant de drogue. Il est plein de rage et ses notes en classe ont chuté !

- Et toi, qu'en penses-tu?

- La police est débordée, sous-financée, mal encadrée, mal entraînée mais ce n’est pas une raison pour oublier mon Marco. Pour les policiers, Marco était membre d'un gang de rue. Ils n'admettront jamais que trouver son meurtrier n'est pas une priorité. Pourtant la rage de son petit frère Firmin en est une. La colère des autres jeunes hommes noirs aussi. Tu sais comment les ados du quartier surnomment la rue en face de chez moi ? « La bande de Gaza ». Ça, on ne le dit jamais à la télé. Tu es un reporter de guerre en temps de paix.

- Quel est le message que tu veux faire parvenir aux enquêteurs?

- Il n'y aura pas de paix dans mon quartier sans justice. Et dire que je suis venu au Canada pour fuir l'injustice.

En sortant, Sylvestre lui donna une photo de son fils. Marco montrait fièrement un travail de rédaction avec une bonne note.

Le pire dans cette histoire est que Guillaume n'a jamais pu passer cette entrevue en ondes. Ce n'était pas représentatif d'un «problème endémique ». C'est ainsi que son supérieur avait expliqué son refus. Il aurait fallu parler au syndicat des policiers, à un sociologue et un spécialiste de la toxicomanie. Après tout ça, Guillaume aurait eu à citer des statistiques sur le trafic des armes à feu.

Le reporter ne voulait pas parler d'un problème endémique. Le journaliste souhaitait faire entendre la douleur d'un père africain qui ne savait plus s'il avait bien fait de venir dans ce pays qui lui avait arraché son fils. Il voulait montrer un homme qui pleurait à l'intérieur de ses mots. Un père qui voulait que son fils Marco soit le dernier des jeunes Noirs à mourir dans l'indifférence. 
Le vrai problème endémique, pensa Guillaume, était son renvoi de la radio de RadioCanada. Combien de minorités visibles sont-elles dans les médias ? C'était aussi la violence policière qui terrorise les Noirs comme Sylvestre, incapable de les appeler au secours. 